\title{
Performance of Electrocoagulation Processes for the Removal of COD and Ammonia from High Salinity Landfill-leachate using Iron or Aluminum Electrodes
}

\author{
D. Marmanis ${ }^{1, *}$, A. Thysiadou ${ }^{1}$, V. Diamantis ${ }^{2}$, A. Christoforidis ${ }^{1}$ and K. Dermentzis ${ }^{1}$ \\ ${ }^{1}$ Department of Chemistry, International Hellenic University, Kavala, Greece \\ ${ }^{2}$ Department of Environmental Engineering, Democritus University of Thrace, GR67100 Xanthi, Greece.
}

Received 19 February 2020; Accepted 24 August 2021

\begin{abstract}
Landfill leachate is characterized by a large fraction of low biodegradability organics. The present work aimed to evaluate and optimize the electrocoagulation (EC) process to remove chemical oxygen demand (COD) and $\mathrm{NH}_{4}-\mathrm{N}$ from highsalinity landfill leachate. The study was conducted using iron or aluminum electrodes while different parameters such as reaction time, current density, and $\mathrm{pH}$ were evaluated on the process's efficiency. The experimental results showed that by applying a current density of $12 \mathrm{mAcm}^{-2}$, the COD removal after 240 minute electro-processing time was $78.5 \%$ and $72.5 \%$ for iron and aluminum electrodes respectively. Also, the removal of $\mathrm{NH}_{4}-\mathrm{N}$ after 240 minutes at a current density of 12 $\mathrm{mA} \mathrm{cm}{ }^{2}$ was $62 \%$ and $54 \%$ for iron and aluminum electrodes respectively. This study demonstrates the feasibility of electrocoagulation to treat high-salinity landfill leachate without the need for a supporting electrolyte.
\end{abstract}

Keywords: landfill leachate; electrocoagulation; aluminum and iron electrodes

\section{Introduction}

Sanitary landfills consist of one of the most applied solutions for municipal and industrial solid waste disposal. Undeniably, landfills contribute to gaseous (carbon dioxide, methane, and nitrous oxides) and liquid emissions (leachate), the latter being rich in organic and inorganic compounds, heavy metals, and other anthropogenic chemicals that can severely contaminate soils and freshwater bodies [1].

There is no typical composition for landfill leachate samples, and this is closely related to the landfill-age, the weather conditions prevailing on-site, the type and composition of solid wastes disposed therein, the moisture content of the waste body, and the availability of oxygen [2]. The biodegradability of landfill-leachate is affected by the landfill-age, and it is evaluated according to the BOD/COD ratio. Old landfill leachates ( $>10-15$ years) are characterized by $\mathrm{BOD} / \mathrm{COD}$ ratio between 0.05 and 0.20 , while for young landfills $(<5$ years $)$ this value is often higher than $0.50[3]$.

Landfill-leachate requires appropriate treatment before disposal to the environment. Several technologies have been applied for landfill-leachate treatment, including physical, chemical, and biological processes [4]. In some cases, landfill-leachate is co-treated with sewage at municipal wastewater treatment plants [5]. During the last years, electrochemical technologies were proposed as an alternative treatment approaches. Electrocoagulation is an advanced treatment process that combines electrochemical methods with conventional chemical coagulation to remove organic and inorganic compounds from landfill leachates [6-10]. During the electrocoagulation process, metallic ions are released into the wastewater by the applied electrical current and subsequently hydrolyzed to generate the desired coagulating species. Therefore, the coagulants are not

*E-mail address: marmanis@chem.ihu.gr

ISSN: 1791-2377 @ 2021 School of Science, IHU. All rights reserved. doi:10.25103/jestr.144.14 supplemented externally into the solution, rather than generated in-situ following electro-dissolution of the aluminum or iron anodes [11].

During the electrocoagulation process with iron and aluminum electrodes, the following reactions occur:

A) Iron electrodes:

$$
\begin{aligned}
& \mathrm{Fe} \rightarrow \mathrm{Fe}^{2+}+2 \mathrm{e} \quad \text { (anode) } \\
& \mathrm{Fe} \rightarrow \mathrm{Fe}^{3+}+3 \mathrm{e} \quad \text { (anode) } \\
& 2 \mathrm{H}_{2} \mathrm{O}+2 \mathrm{e} \rightarrow \quad \mathrm{H}_{2}+2 \mathrm{OH}^{-} \quad \text { (cathode) } \\
& \mathrm{Fe}^{2+}+2 \mathrm{OH}^{-} \rightarrow \mathrm{Fe}(\mathrm{OH})_{2} \quad \text { (coagulant) } \\
& \mathrm{Fe}^{3+}+3 \mathrm{OH}^{-} \rightarrow \mathrm{Fe}(\mathrm{OH})_{3} \quad \text { (coagulant) }
\end{aligned}
$$

B) Aluminum electrodes:

$\mathrm{Al} \rightarrow \mathrm{Al}^{3+}+3 \mathrm{e}^{\text {(anode) }}$

$2 \mathrm{H}_{2} \mathrm{O}+2 \mathrm{e} \rightarrow \mathrm{H}_{2}+2 \mathrm{OH} \quad$ (cathode)

$\mathrm{Al}^{3+}+3 \mathrm{OH}^{-} \rightarrow \mathrm{Al}(\mathrm{OH})_{3} \quad$ (coagulant)

The produced metallic cations $\mathrm{Fe}^{2+}, \mathrm{Fe}^{3+}$ and $\mathrm{Al}^{3+}$ from the corresponding anodic reactions (1), (2) and (6) induce a reduction of the colloidal matter's net surface charge resulting in destabilization followed by coagulation. Furthermore, $\mathrm{Fe}^{2+}, \mathrm{Fe}^{3+}$ and $\mathrm{Al}^{3+}$ cations combine with the cathodically generated $\mathrm{OH}^{-}$anions according to the reactions (4), (5) and (8) to form the known coagulant precipitates, $\mathrm{Fe}(\mathrm{OH})_{2}$, $\mathrm{Fe}(\mathrm{OH})_{3}$ and $\mathrm{Al}(\mathrm{OH})_{3}$ that are capable of adsorbing both organic and inorganic pollutants [12,13]. Simultaneously hydrogen gas bubbles are generated at the cathode contributing to the flotation of particulate matter and flocs. The sludge formed can be further separated from the treated solution either by filtration or centrifugation. Based on the 
above, the electrocoagulation removal of pollutants may involve mechanisms such as oxidation, reduction, coagulation, absorption, flotation, and precipitation[14,15].

The present study aimed to evaluate the electrocoagulation process for high-salinity landfill-leachate processing. The study focused on the effect of electrode type, the applied current density, processing time and $\mathrm{pH}$, in relation to the removal of ammonia and COD. Finally a comparison with similar studies reported in the literature was performed.

\section{Material and Methods}

\subsection{Leachate and reagents}

The leachate samples used for this study were obtained from a sanitary landfill located in North Greece. The site was in operation since 2005 and received both municipal, industrial, and agro-industrial wastes and sludges. The reagents used for $\mathrm{pH}$ adjustment $(\mathrm{HCl}, \mathrm{NaOH})$ were all of analytical grade (Merck).

\subsection{Experimental design and apparatus}

Electrocoagulation experiments were conducted at room temperature using a cylindrical electrochemical reactor $(250$ $\mathrm{mL}$ working volume) equipped with a magnetic stirrer (Thermodyne, Nuova II Stir Plate), operated at $300 \mathrm{rpm}$. Two commercially iron (St 37-2 steel) (according to German standard DIN 17100) or aluminum plates (2024 aluminum alloy) were used as electrodes with size $8 \times 5 \times 0.3 \mathrm{~cm}$ and an effective area of $25 \mathrm{~cm}^{2}$ each. The electrodes were placed vertically parallel to each other, having an inter-electrode distance of $1 \mathrm{~cm}$. The electrodes were connected to a DC power supply (STELLTRAFO, PHYWE SystemeGmbh\&Co, Germany) to provide constant current and a multimeter (VOLTCRAFT 91) measuring electron potential and current.
The efficiency of the electrocoagulation treatment during landfill leachate processing was studied for different current densities $\left(12,24\right.$, and $\left.36 \mathrm{~mA} \mathrm{~cm}^{-2}\right)$, electro-processing time $(50,100,150,200$, and $240 \mathrm{~min})$, type of electrodes (iron and aluminum) and various initial solution $\mathrm{pH}$ values. Every 50 minutes of electro-processing time, liquid samples were extracted from the reactor medium, filtered with whatman paper, and analyzed for $\mathrm{pH}$, electrical conductivity, chemical oxygen demand (COD), and ammonia nitrogen $\left(\mathrm{NH}_{4}-\mathrm{N}\right)$. COD measurements were performed using a COD thermoreactor ( $\operatorname{Tr} 420$, Merk) and a spectrophotometer (Spectroquant Pharo100, Merk), according to the Standard Methods for examination of water and wastewater.

\section{Results and discussion}

\subsection{Landfill-leachate characteristics}

The main characteristics of the landfill-leachate used for this study are shown in Table 1 . The BOD/COD ratio was equal to 0.15 , indicating that the landfill was old; besides, it is in operation for more than 15 years. Similar leachate composition was recorded in municipal solid waste landfills in Brazil, India and Malaysia (see Table 1). Based on the results from Table 1 landfill leachate electrical conductivity may vary from 5 up to $35 \mathrm{mS} \mathrm{cm}^{-1}$. In our case, the leachate's high electrical conductivity was attributed to the implementation of reverse osmosis for leachate processing, where the generated concentrates were continuously recirculated back onto the landfill body. In a similar case study, a significant increase of the leachate chlorides concentration from 2.18 to $3.52 \mathrm{~g} \mathrm{~L}^{-1}$ was observed after implementing reverse osmosis with recirculation of the concentrates onto the landfill body [16].

Table 1. Physicochemical properties of landfill-leachate from different origin. The numbers in parenthesis for the landfill leachate used for this study indicate the standard deviation $(n=10)$.

\begin{tabular}{|c|c|c|c|c|c|c|}
\hline Landfill site & Greece & Canada & China & Malaysia & Brazil & India \\
\hline Waste origin & $\mathrm{MSW}+\mathrm{ISW}+\mathrm{SS}$ & MSW & $\mathrm{nr}$ & MSW & MSW & $\mathrm{nr}$ \\
\hline Commissioning & 2005 & 2000 & 2005 & 2005 & 2007 & 2013 \\
\hline pH (-) & $7.54( \pm 0.35)$ & 7.83 & $\mathrm{nr}$ & 8.17 & 7.90 & 8.64 \\
\hline $\mathrm{EC}\left(\mathrm{mS} \mathrm{cm}^{-1}\right)$ & $25.8( \pm 1.9)$ & 5.29 & $\mathrm{nr}$ & 29.2 & 7.94 & 36.5 \\
\hline BOD $\left(\mathrm{mg} \mathrm{L}^{-1}\right)$ & $1300( \pm 880)$ & 460 & 960 & 540 & 923 & 1519 \\
\hline $\operatorname{COD}\left(\mathrm{mg} \mathrm{L}^{-1}\right)$ & $8870( \pm 1360)$ & 1620 & 2566 & 10000 & 4200 & 13760 \\
\hline $\mathrm{NH}_{4}-\mathrm{N}\left(\mathrm{mg} \mathrm{L}^{-1}\right)$ & $872( \pm 200)$ & 653 & 386 & 5800 & 1648 & $\mathrm{nr}$ \\
\hline References & This study & [6] & [7] & [8] & [9] & [10] \\
\hline
\end{tabular}

MSW - municipal solid waste, ISW - industrial solid waste, SS - sewage sludge, nr - not reported

\subsection{Effect of reaction time and applied current density on COD removal}

Figure 1 demonstrates the effect of processing time on COD removal efficiency using iron or aluminum electrodes. For iron electrodes the data reveal that COD removal increased with the applied electro-processing time and with increasing current density. Indeed, maximum COD removal $(78.5 \%)$ was recorded after 240,140 , and 90 min processing time with increasing current density from 12 to 24 and $36 \mathrm{~mA} \mathrm{~cm}^{-2}$ respectively. Similar COD removal $(60 \%)$ was reported in the literature using iron electrodes at $180 \mathrm{~min}$ processing time and $30 \mathrm{~mA} \mathrm{~cm}^{-2}$ current density [17]. Current density affects the rate of coagulants' release (by the anode) and hydrogen gas production (by the cathode). The latter can adsorb to particulate and flocculent matter, causing flotation. A study conducted at low current density $(3 \mathrm{~mA} \mathrm{~cm})$ resulted in a COD removal of $33 \%$ after $50 \mathrm{~min}$ [18] while at a current density of $16 \mathrm{~mA} \mathrm{~cm}^{-2}$, COD removal was $40 \%$ after $90 \mathrm{~min}$ of electrocoagulation time [19], which is comparable with the results of this work. The current density increases the electron's flow velocity due to ions' electrostatic attraction through the oppositely charged electrodes, further increasing the coagulant dosage. According to Bouhezila et al.[20] the amount of coagulant flocs (sludge) increased from 16 to $60 \%$ $(\mathrm{v} / \mathrm{v})$ with increasing current density from 12 and $40 \mathrm{~mA} \mathrm{~cm}^{-}$ 2 .

For aluminum electrodes, COD removal efficiency increased with the applied current density (see Figure 1b). In 
this case, maximum COD removal $(72.5 \%)$ was recorded after 240, 140, and 90 min processing time, at an applied current density of 12,24 and $36 \mathrm{~mA} \mathrm{~cm}^{-2}$, respectively. As evidenced by the results presented therein, up to $72 \% \mathrm{COD}$ removal is possible within $240 \mathrm{~min}$ processing time. Based on previous studies, landfill leachate COD removal efficiency increased from 40 to 60 and $65 \%$ using aluminum electrodes, with increasing current density from 16 to 38 and $50 \mathrm{~mA} \mathrm{~cm}^{-}$ ${ }^{2}$ respectively, which is within the same range with the results of this work.
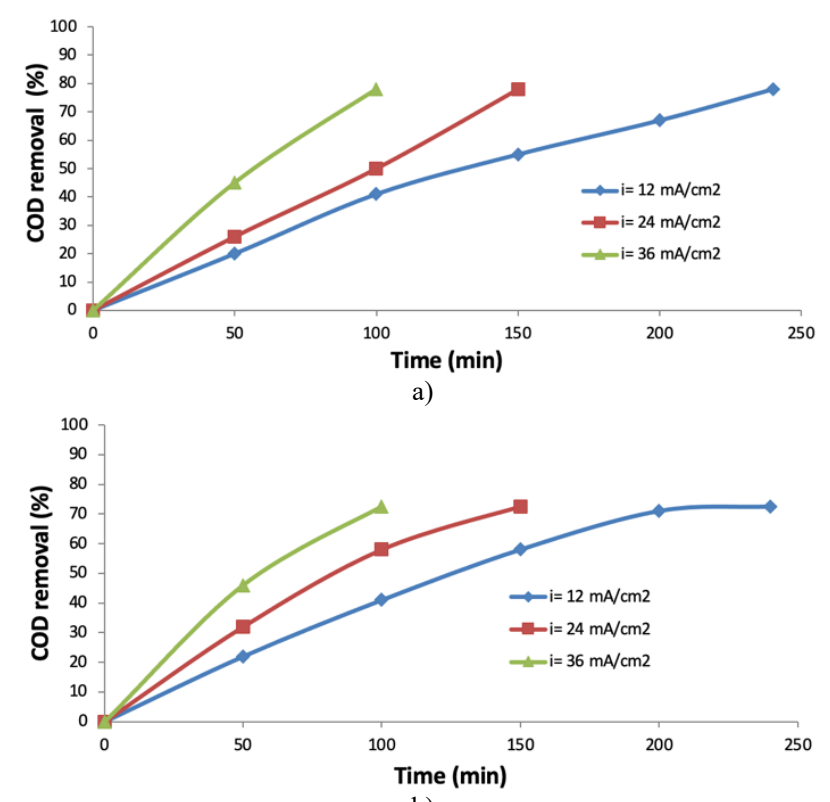

b)

Fig. 1. COD removal efficiency as a function of time at various current densities for landfill leachate electrocoagulation with a) iron and b) aluminum electrodes.

The time required to achieve the desired removal efficiency is essential for the design of an electrochemical treatment technology. The electrocoagulation process is separated into two phases, coagulation (destabilization of charged colloidal particles) and flocculation (aggregation of colloids), with the first being accomplished within a short time period (usually between 5 and 10 min depending on the rate of coagulant release) and the second between 20-50 min depending on the mixing conditions inside the reactor $[15$, 21]. The $\mathrm{Fe}^{2+}, \mathrm{Fe}^{3+}$ and $\mathrm{Al}^{3+}$ ions released by electrodissolution of the anodes are well known to decrease colloids' net surface charge. A short operating time results in low charge neutralization, and the produced metal ions are not enough to destabilize the colloids. Therefore, increasing processing time is generally related to higher COD removal since more iron or aluminum cations are released, which act as the coagulant. Moreover, flotation of the precipitates and flocs formed occurs by the generated hydrogen gas bubbles, resulting in additional separation of the organics [7, 22, 23]. As shown in the data provided in Table 2, the implementation of iron or aluminum electrodes resulted in a significant increase of the solution electrical conductivity. This was attributed to the release of coagulants. According to Bouhezila et al[20] iron electrodes were more efficient than aluminum electrodesto remove COD under the same operating conditions, which is consistent with the results of this work. Also, iron is less toxic and acceptable in case that the treated effluent is reusedin agriculture.

\subsection{Effect of initial pH}

As observed in previous studies, the solution's initial $\mathrm{pH}$ is a critical factor influencing the efficiency of the electrocoagulation process (e.g. $[18,19])$. According to the data presented in Table 3 (for iron electrodes), it becomes evident that the leachate solution's $\mathrm{pH}$ increases during the electrochemical treatment. Galvao et al [19] reported a similar $\mathrm{pH}$ increase from 7.9 to 9.0 during electrocoagulation of landfill leachate at $13 \mathrm{~mA} \mathrm{~cm}$ and 90 min processing time. Other studies showed that for initial $\mathrm{pH}$ values between 4 and 7 , the observed increase of solution $\mathrm{pH}$ was attributed to the generation of $\mathrm{OH}-$ ions at the cathode $[24,25]$.

Table 2. Evolution of the electrical conductivity (EC), temperature and COD during landfill-leachate processing with iron or aluminum electrodes at a current density $36 \mathrm{~mA}$ $\mathrm{cm}^{-2}$.

\begin{tabular}{c|c|c|c}
\hline Time (min) & EC $\left(\mathbf{m S c m}^{-1}\right)$ & $\mathbf{T ~}\left({ }^{\mathbf{}} \mathbf{C}\right)$ & $\mathbf{C O D}\left(\mathbf{m g L}^{\mathbf{- 1}}\right)$ \\
\hline \multicolumn{4}{c}{ Iron electrodes } \\
\hline 0 & 25,8 & 28 & 9890 \\
50 & 26,5 & 29 & 4850 \\
100 & 26,9 & 30 & 2130 \\
150 & 27,8 & 30.6 & 1580 \\
200 & 28,2 & 32 & 1167 \\
240 & 30,4 & 33 & 927 \\
\hline \multicolumn{4}{c}{ Aluminum electrodes } \\
\hline 0 & 25,8 & 28 & 9890 \\
50 & 30,6 & 34 & 5440 \\
100 & 31,2 & 37 & 2715 \\
150 & 32,1 & 38 & 2374 \\
200 & 32,4 & 39 & 2067 \\
240 & 32,5 & 39,5 & 1854 \\
\hline
\end{tabular}

According to Figure 2, the optimal initial $\mathrm{pH}$ was recorded between 6 and 8, where the coagulants' hydroxide form $\mathrm{Fe}(\mathrm{OH})_{2}, \mathrm{Fe}(\mathrm{OH})_{3}$ and $\mathrm{Al}(\mathrm{OH})_{3}$ prevails. This is within the range of typical leachate samples (see Table 1). At $\mathrm{pH}<3$ (acidic conditions) and $\mathrm{pH}>9$ (basic conditions), the corresponding cationic form, $\mathrm{Fe}^{2+}, \mathrm{Fe}^{3+} \mathrm{Al}^{3+}$ and a series of polymeric anionic forms, especially for aluminum, are predominant, which do not favor the coagulation process. Under acidic conditions, the removal efficiency of aluminum is equal or even better compared to iron, due to enhanced tendency for production of more $\mathrm{Fe}^{2+}$ than $\mathrm{Fe}^{3+}$ ions. Indeed, ferrous ions are weaker coagulants compared to ferric ions.Similar to our results, $\mathrm{Li}$ et al [18] and $\mathrm{Le}$ et al [26]observed that the optimum $\mathrm{pH}$ conditions for landfill leachate electrocoagulation was between 6 and 8 using iron or aluminum electrodes.

Table 3. Evolution of $\mathrm{pH}$ and COD removalas a function of time for landfill leachate electrocoagulation with iron electrodes at $12 \mathrm{~mA} \mathrm{~cm}^{-2}$ current density.

\begin{tabular}{c|c|c}
\hline $\begin{array}{c}\text { Processing time } \\
\text { (min) }\end{array}$ & pH & $\begin{array}{c}\text { CODRemoval } \\
(\mathbf{\%})\end{array}$ \\
\hline 0 & 7.54 & 0 \\
50 & 8.64 & 22 \\
100 & 8.86 & 40 \\
150 & 9.15 & 56 \\
200 & 9.43 & 73 \\
240 & 9.52 & 78.5 \\
\hline
\end{tabular}




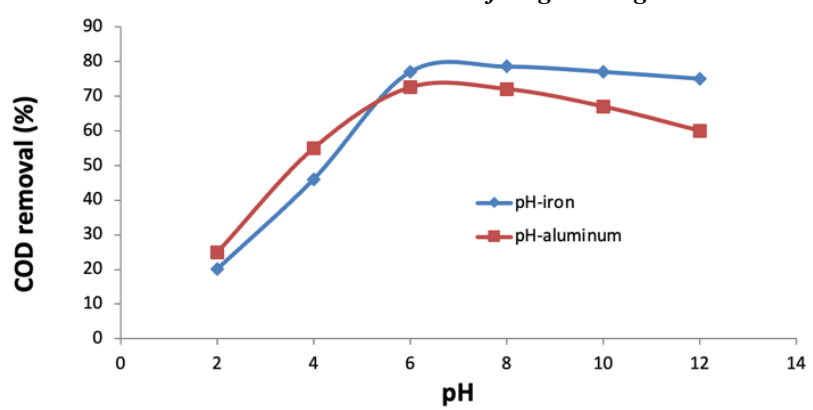

Fig. 2. Effect of solution $\mathrm{pH}$ on $\mathrm{COD}$ removal efficiency for landfill leachate electrocoagulation with iron and aluminum electrodes at $12 \mathrm{~mA}$ $\mathrm{cm}^{-2}$ current density and $240 \mathrm{~min}$ processing time.
3.4. Effect of reaction time,type of electrodes and applied current density on $\mathrm{NH}_{4}-\mathrm{N}$ removal

Figure 3 shows that increasing current density was beneficial for $\mathrm{NH}_{4}-\mathrm{N}$ removal. Considering the treatment conditions applied in this study ( $\mathrm{pH}=7.54$, and reaction time $240 \mathrm{~min}$ ), iron electrodes were more effective than aluminum for $\mathrm{NH}_{4-}$ $\mathrm{N}$ removal. Indeed, after 240 min of electro-processing time at $12 \mathrm{~mA} \mathrm{~cm}^{-2}$ current density, maximum $\mathrm{NH}_{4}-\mathrm{N}$ removal efficiency was $62 \%$ and $54 \%$ for iron and aluminum electrodes, respectively. Based on the results from previous studies, ammonia nitrogen removal efficiency ranged between 6 and 50\% (see Table 4). Most of these studies, however, were conducted at low electro-processing time (often less than $60 \mathrm{~min}$ ). The removal of ammonia is generally attributed to the increase in solution $\mathrm{pH}$, which in turns favor ammonia stripping by the generated hydrogen bubbles.

Table 4. Comparison of $\mathrm{NH}_{4}-\mathrm{N}$ removal efficiency during landfill leachate electrocoagulation using iron or aluminum electrodes at different processing times and current densities.

\begin{tabular}{|c|c|c|c|c|c|c|c|}
\hline \multicolumn{2}{|c|}{ Leachate } & \multicolumn{2}{|c|}{ Equipment } & \multicolumn{2}{|c|}{ Conditions } & \multirow{2}{*}{$\begin{array}{c}\text { Removal } \\
\mathrm{NH}_{4}-\mathrm{N} \\
(\%)\end{array}$} & \multirow[b]{2}{*}{ References } \\
\hline $\begin{array}{l}\mathrm{NH}_{4}-\mathrm{N} \\
(\mathrm{mg} / \mathrm{L})\end{array}$ & pH (-) & $\begin{array}{c}\text { Anode } \\
\text { material }\end{array}$ & $\begin{array}{l}\text { Cathode } \\
\text { material }\end{array}$ & $\begin{array}{l}\text { Time } \\
\text { (min) }\end{array}$ & $\begin{array}{c}\text { Current } \\
\left.(\mathrm{mA} \mathrm{cm})^{-2}\right)\end{array}$ & & \\
\hline 653 & 7.83 & Aluminum & Stainless steel & 30 & 15 & 6 & [27] \\
\hline 1615 & 8.25 & Aluminum & Aluminum & 30 & 50 & 15 & [20] \\
\hline 386 & 6.85 & Aluminum & Aluminum & 50 & 3 & 24 & [18] \\
\hline 216 & 8.24 & Aluminum & Aluminum & 60 & 38 & 40 & [28] \\
\hline 980 & 8.30 & Aluminum & Aluminum & 120 & 50 & 30 & [10] \\
\hline 872 & 7.54 & Aluminum & Aluminum & 240 & 36 & 54 & This study \\
\hline 1615 & 8.25 & Iron & Iron & 30 & 50 & 24 & {$[20]$} \\
\hline 386 & 6.85 & Iron & Iron & 50 & 3 & 28 & {$[18]$} \\
\hline 1256 & 8.00 & Iron & Stainless steel & 60 & 0.4 & 27 & [26] \\
\hline 3000 & 6.50 & Iron & Aluminum & 60 & 56 & 50 & [29] \\
\hline 872 & 7.54 & Iron & Iron & 240 & 36 & 62 & This study \\
\hline
\end{tabular}

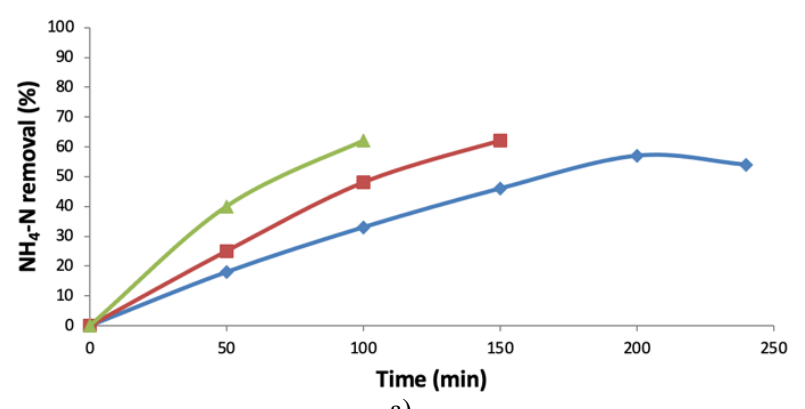

a)

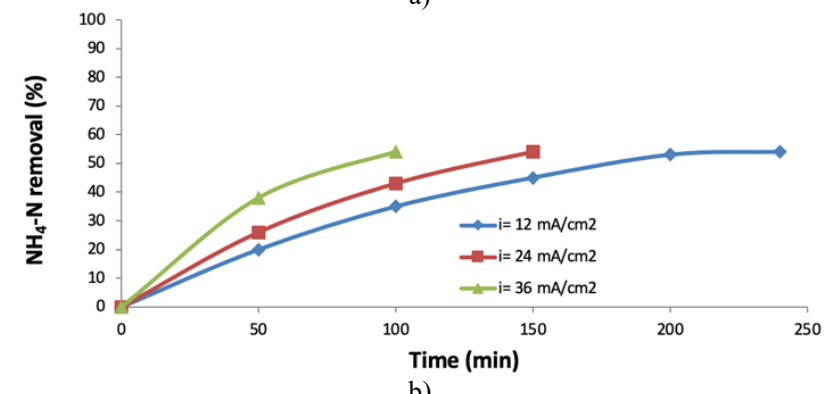

b)

Fig. 3. Effect of current density and processing time on $\mathrm{NH}_{4}-\mathrm{N}$ removal efficiency for landfill leachate electrocoagulation with a) iron and b) aluminum electrodes.

\section{Conclusions}

This study indicates that the electrocoagulation process was efficient for COD and ammonia nitrogen removal from a high-salinity landfill-leachate. The experimental results showed that the treatment efficiency increases proportionally with increasing the applied current density and reaction time. Furthermore, it was found that iron electrodes were more effective compared to aluminum electrodes, especially at higher applied current density. Compared to similar studies it was observed that ammonia nitrogen removal is favored at high electro-processing times. Electrocoagulation consist an interesting technology for pollutants removal from leachates. Future studies should focus on field-scale applications to further evaluate long term efficiency and the costs involved.

This is an Open Access article distributed under the terms of the Creative Commons Attribution License.

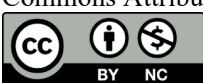

\section{References}

1. Calabro P.S., Komilis D., A standardized inspection methodology to evaluate municipal solid waste collection performance. J. Environ. Manage. 246 (2019) 184-191.

2. Abbas A.A., Jingsong G., Ping L.Z., Ya P.Y., Al-Rekabi W.S., Review on landfill leachate treatments, Am. J. Appl. Sci. 6 (2009)672-684.
3. Wiszniowski J., Robert D., Surmacz-Gorska J., Miksch K., Weber J.V., Landfill leachate treatment methods: a review. Environ. Chem. Lett. 4 (2006) 51-61.

4. Kurniawan T.A., Lo W., Chan G., Sillanpaa M.E.T., Biological processes for treatment of landfill leachate. J. Environ. Monitor. 12 (2010) 2032-2047. 
D. Marmanis, A. Thysiadou, V. Diamantis, A. Christoforidis and K. Dermentzis/

\section{Journal of Engineering Science and Technology Review 14 (4) (2021) 105 - 109}

5. Deng Y., Englehardt J.D., Electrochemical oxidation for landfill leachate treatment, Waste Manage. 27 (2007) 380-388.

6. Huda N., Raman A.A.A., Bello M.M., Ramesh S., Electrocoagulation treatment of raw landfill leachate using iron-based electrodes: effects of process parameters and optimization. J. Environ. Manage. 204(2017) 75-81.

7. Alver A., Altas L., Characterization and electrocoagulative treatment of landfill leachates: a statistical approach. Process Saf. Environ. 111(2017) 102-111.

8. Bharath M., Krishna B.M., Kumar B.M., Degradation and biodegradability improvement of the landfill leachate using electrocoagulation with iron and aluminum electrodes: a comparative study. Water Practice Technology 15(2020) 540-549.

9. Faheem K., Khan S.U., Washeem M., Khan S.U., Energy efficient removal of COD from landfill leachate wastewater using electrocoagulation: parametric optimization using RSM. Int. J.Environ. Sci. Tech. (2021) https://doi.org/10.1007/s13762-02103277-3.

10. Kallel A., Attour A., Trabelsi I., Electro-coagulation treatment of raw and autoclaved landfill leachate with aluminum electrodes: case study of Djebel Chakri (Tunisia). Arab. J. Geosci. 10(2017) 85.

11. Dermentzis K., Valsamidou E., Lazaridou A.,Kokkinos N., Nickel removal from wastewater by electrocoagulation with aluminum electrodes. J. Eng. Sci.Technol. Rev. 4(2011) 188-192.

12. Dermentzis K., Removal of nickel from electroplating rinse waters using electrostatic shielding electrodialysis/ electrodeionization, J. Hazard. Mater. 173 (2010) 647-652.

13. Hossain M., Mahmud I., Parvez S., Cho H.M., Impact of current density, operating time and $\mathrm{pH}$ of textile wastewater treatment by electrocoagulation process, Environ. Eng. Res. 18 (2013) 157-161.

14. MarmanisD., DermentzisK., ChristoforidisA., OuzounisK., MoumtzakisA.,Electrochemical treatment of actual dye house effluents using electrocoagulation process directly powered by photovoltaic energy, Desalin. Water Treat.56 (2015) 2988-2993.

15. Vepsalainen M., Sillanpaa M., Chapter 1 - Electrocoagulation in the treatment of industrial waters and wastewaters. In: Sillanpaa M. (ed) Advanced water treatment,(2020) Elsevier, pp 1-78.

16. CalabroP.S., Gentili E., Meoni C., Orsi S., Komilis D., Effect of the recirculation of a reverse osmosis concentrate on leachate generation: a case study in an Italian landfill. Waste Manage. 76 (2018) 643-651.

17. Orkun M.O., Kuleyin A., Treatment performance evaluation of chemical oxygen demand from landfill leachate by electro- coagulation and electro-fenton technique. Environ. Prog. Sustain. 31(2012) 59-67.

18. Li X., Song J., Guo J., Wang Z., Feng Q., Landfill leachate treatment using electrocoagulation. Procedia Environ. Sci. 10(2011) 11591164.

19. Galvao N., de Souza J.B., de Souza Vidal C.M., Landfill leachate treatment by electrocoagulation: effects of current density and electrolysis time. J. Environ. Chem. Eng. 8(2020) 104368.

20. Bouhezila F., Hariti M., Lounici H., Mameri N., Treatment of the OUED SMAR town landfill leachate by an electrochemical reactor, Desalination 280(2011) 347- 353.

21.DermentzisK., ChristoforidisA., ValsamidouE., LazaridouA., KokkinosN., Removal of hexavalent chromium from aqueous industrial metal plating wastewaters by chemical and electrochemical coagulation, Global Nest J. 13 (2011) 412-418.

22. Kobya M., Demirbas E., Parlak N.U., Yigit S.,Treatment of cadmium and nickel electroplating rinse water by electrocoagulation, Environ. Technol. 31 (2010) 1471-1481.

23. DermentzisK., Karakosta K., KoshelevaR., KokkinosN., Electrochemical Remediation of Phthalocyanine Dye Wastewater and simultaneous Hydrogen Production, J. Eng. Sci. Technol. Rev. 13(6) (2020), 22-25.

24. Koshla N.K., Venkatachalam S., Somasundaran P., Pulsed electrogeneration of bubbles for electroflotation, J. Appl. Electrochem. 21 (1991) 986-990.

25. VlyssidesA.G., KarlisP.K.,MahnkenG.,Influence of various parameters on the electrochemical treatment of landfill leachates, J. Appl. Electrochem. 33 (2003) 155-159.

26. Le T.S., Dang N.M., Tran D.T., Performance of coupling electrocoagulation and biofiltration processes for the treatment of leachate from the largest landfill in Hanoi, Vietnam: impact of operating conditions. Sep. Purif. Technol. 255(2021) 117677.

27. Dia O., Drogui P., Buelna G., Dube R., Hybrid process, electrocoagulation-biofiltration for landfill leachate treatment. Waste Manage. 75(2018) 391-399.

28. Niza N.M., Yusoff M.S., Zainuri M.A.A.M., Emmanuel M.I., Shadi A.M.H.S., Hanif M.H.M., Kamaruddin M.A., Removal of ammoniacal nitrogen from old leachate using batch electrocoagulation with vibration-induced electrode plate. J. Environ. Chem. Eng. 9(2021)105064.

29. Pirsaheb M., Azizi E., Almasi A., Soltanian M., Khosravi T., Ghayebzadeh M., Sharafi K., Evaluating the efficiency of electrochemical process in removing COD and NH4-N from landfill leachate. Desalin. Water Treat. 57 (2016) 6644-6651. 